\title{
STUDI PEMISAHAN BEBAN PENYULANG BARU SKTM GIS PANTAI INDAH KAPUK
}

\author{
Juara Mangapul Tambunan ${ }^{1)}$,Nurmiati Pasra, ST, MT $^{2)}$, Rico Sumander ${ }^{3)}$ \\ Teknik Elektro, Sekolah Tinggi Teknik - PLN \\ 1juaramangapult_stmsi@yahoo.com \\ 2nurmi.pasra@gmail.com \\ 3rider_ngl@yahoo.com
}

\begin{abstract}
With increasing energy needs of electricity for industry and new customers in the crowded settlements, especially along the coastal areas of Beautiful Kapok, readiness and availability of resources to increase the burden of customers need efforts and appropriate measures. One of the most easy and safe to transmit electrical energy is by Splitting the load. The aim in this study is to determine the way and site selection as well as calculate the imposition of new penyulang. The distribution of electric energy from the parent booths toward the consumers can do with the distribution of direct or indirect distribution. Via Penyulang $20 \mathrm{kV}$ distribution with the selected cable channels-free cable is a requirement of the disorder, in an effort to increase the quality of the distribution. In the system of electric power supply, voltage general conditions let it send penyulang allowed (5\%-10\%) according to the standard PLN. While according to ANSI standard C 84 , paragraph 1 is (4\% and-10\%) under normal conditions. The current that flows through the penyulang must not exceed the limit of the ability distribution against the denseness of the load. So that the required voltage quality is better. As for who should be taken into account in determining the location of the new building of the penyulang is based on the Division of the burden, then choose the type of cable that well that is kind of XLPE cable $240 \mathrm{~mm} 2$ aluminum as a necessary investment.
\end{abstract}

Keywords: Splitting the load, New Penyulang, Underground Cable Ducts, XLPE cable

\begin{abstract}
Abstrak : Seiring dengan meningkatnya kebutuhan energi listrik bagi industri dan pelanggan baru pada pemukiman padat penduduk, khususnya di sepanjang wilayah Pantai Indah Kapuk, kesiapan dan ketersediaan daya untuk pertambahan beban pelanggan perlu dilakukan upaya dan langkah yang tepat. Salah satu cara yang paling mudah dan aman untuk mengirimkan energi listrik adalah dengan Pemisahan Beban. Tujuan yang dilakukan dalam penelitian ini yaitu untuk menentukan cara dan pemilihan lokasi serta menghitung pembebanan penyulang baru. Penyaluran energi listrik dari gardu induk menuju konsumen dapat dilakukan dengan pendistribusian langsung maupun pendistribusian tidak langsung. Melalui Penyulang distribusi $20 \mathrm{kV}$ dengan saluran kabel yang dipilih merupakan syarat bebasnya kabel dari gangguan, sebagai upaya peningkatan kualitas pendistribusian. Dalam sistem penyediaan tenaga listrik, syarat umum tegangan listrik diujung kirim penyulang yang diijinkan (+5\% dan $-10 \%)$ sesuai standar PLN. Sedangkan menurut standar ANSI C 84 ayat 1, adalah (+4\% dan $-10 \%)$ dalam kondisi normal. Arus yang mengalir melalui penyulang tidak boleh melebihi batas kemampuan penyaluran terhadap padatnya beban. Sehingga diperlukan kualitas tegangan yang lebih baik. Adapun yang harus diperhitungkan dalam menentukan lokasi dibangunnya penyulang baru adalah berdasarkan pembagian beban, setelah itu memilih jenis kabel yang baik yaitu jenis kabel XLPE berpenghantar aluminium $240 \mathrm{~mm}^{2}$ sebagai investasi yang diperlukan.
\end{abstract}

Kata Kunci : Pemisahan Beban, Penyulang Baru, SKTM, Kabel XLPE 


\section{PENDAHULUAN}

Dengan semakin cepatnya perkembangan arus informasi teknologi, sejalan dengan meningkatnya perkembangan kebutuhan akan listrik bagi kehidupan masyarakat yang menjadi kebutuhan yang sangat penting untuk memudahkan berbagai kegiatan, seperti peningkatan kebutuhan listrik bagi industri dan peningkatan pemasangan baru bagi perumahan/pelanggan. Dengan kondisi ini maka dibutuhkan solusi yang cepat dan akurat untuk mengatasi masalah tersebut. Maka diperlukan penambahan tenaga listrik baru agar kebutuhan listrik di masyarakat dapat terpenuhi.

Pembangunan penyulang baru menjadi bagian yang sangat krusial dalam mengatasi pertumbuhan kebutuhan listrik yang cukup pesat. Penyulang sendiri merupakan bagian dari pendistribusian tenaga listrik dari Gardu Induk untuk sampai menuju konsumen. Perencanaan diperlukan, karena berhubungan dengan tujuan pengembangan sistem distribusi yang harus memenuhi berbagai kriteria teknis dan ekonomis. Perencanaan pembangunan penyulang baru harus dilakukan dengan sangat sistemik dengan pendekatan yang didasarkan pada peramalan beban guna mendapatkan hasil yang optimal. Perencanaan dengan sistemik mampu mengurangi hambatan selama berlangsungnya proses pembangunan.

Potensi dalam perencanaan pembangunan penyulang baru ini semakin diperlukan bila digabungkan dengan investasi terhadap energi, peralatan, dan tenaga kerja.

Pantai Indah Kapuk merupakan salah satu bagian dari wilayah perkotaan yang berkembang dan sangat ramai, banyak industri besar, pasar, mall dan gedung perkantoran. Untuk memenuhi kebutuhan listrik daerah Pantai Indah Kapuk kemungkinan akan semakin berkembang dan membantu pasokan tenaga listrik untuk daerah lain perlu dilakukan penarikan penyulang baru dari tiga unit trafo tersebut.

Tujuan dari penelitian ini adalah untuk mengetahui cara merencanakan pembangunan penyulang baru, serta mengetahui perbaikan nilai tegangan setelah dipecah beban di GIS Pantai Indah Kapuk.

\section{LANDASAN TEORI}

\subsection{Jaringan Tegangan Menengah}

Sistem Distribusi berguna untuk menyalurkan tenaga listrik dari sumber daya listrik besar sampai menuju konsumen. Di mana fungsi Distribusi listrik yaitu membagi atau menyalurkan tenaga listrik ke beberapa tempat (pelanggan). Distribusi listrik merupakan sub system tenaga listrik yang ber-hubungan langsung dengan pelanggan. Karena catu daya pada pusat-pusat beban dilayani langsung melalui jaringan distribusi.

Tenaga listrik yang dihasilkan oleh pembangkit listrik besar dengan tegangan dari $11 \mathrm{kV}$ sampai $24 \mathrm{kV}$ dinaikkan tegangannya oleh gardu induk dengan transformator penaik tegangan menjadi 70 kV, $154 \mathrm{kV}, 220 \mathrm{kV}$ atau $500 \mathrm{kV}$ kemudian disalurkan melalui saluran transmisi. Tujuan menaikkan tegangan adalah untuk memperkecil kerugian daya listrik pada saluran transmisi, dimana dalam hal ini kerugian daya adalah sebanding dengan kuadrat arus yang mengalir. Dengan daya yang sama bila nilai tegangannya diperbesar, maka arus yang mengalir semakin kecil sehingga kerugian daya juga akan kecil pula.

Dari saluran transmisi, tegangan diturunkan lagi menjadi $20 \mathrm{kV}$ dengan transformator penurun tegangan pada gardu induk distribusi, kemudian dengan sistem tegangan tersebut penyaluran tenaga listrik dilakukan oleh saluran distribusi primer atau jaringan tegangan menengah. Dari saluran distribusi primer inilah gardu-gardu distribusi mengambil tegangan untuk diturunkan tegangannya dengan trafo distribusi menjadi sistem tegangan rendah, yaitu $380 / 220$ Volt. Dengan ini jelas bahwa sistem distribusi merupakan bagian yang penting dalam sistem tenaga listrik secara keseluruhan. 


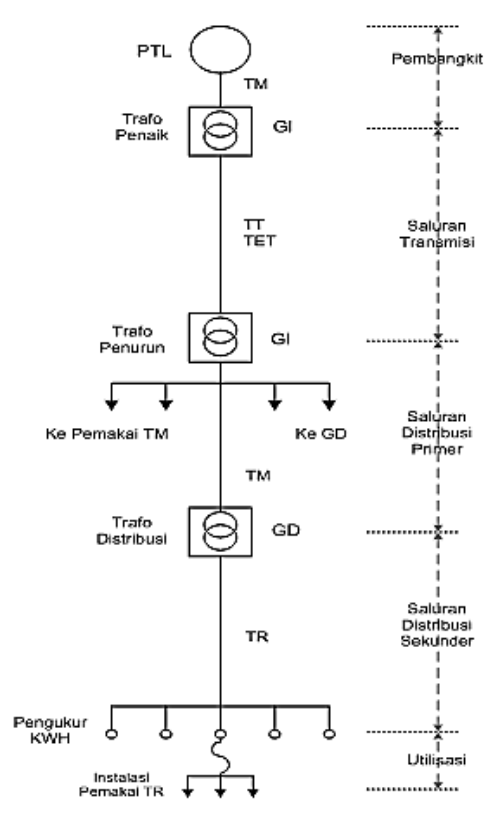

Gambar 2.1 Konfigurasi Sistem Tenaga Listrik

\subsection{Konstruksi Jaringan Tegangan Menengah}

Berdasarkan jenis konstruksi jaringan tegangan menengah terbagi ke dalam tiga jenis, yaitu Saluran Udara Tegangan Menengah (SUTM), Saluran Kabel Tanah Tegangan Menengah (SKTTM), dan Saluran Kabel Udara Tegangan Menengah (SKUTM).

a). Saluran Udara Tegangan Menengah (SUTM) merupakan jaringan kawat tanpa isolasi yang terentang diudara yang disangga oleh tiang penyangga. Secara Umum SUTM digunakan pada daerah dengan kepadatan beban rendah seperti pedesaan dan kota kota kecil. SUTM memiliki jangkauan pelayanan yang luas, murah, dan mudah dibangun, tetapi tingkat keandalaan penyaluran relatif rendah dan tingkat perawatannya tinggi.

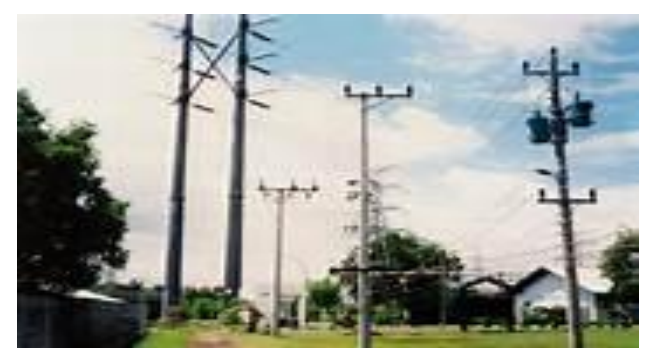

Gambar 2.2 Saluran Udara Tegangan Menengah b). Saluran Kabel Tegangan Menengah (SKTM) merupakan jaringan kabel yang berisolasi yang ditanam didalam tanah sepanjang jaringan. Secara umum, SKTM digunakan pada daerah dengan kepadatan beban tinggi seperti perkotaan. Jaringan penghantar SKTM memiliki tingkat keandalan yang tinggi.

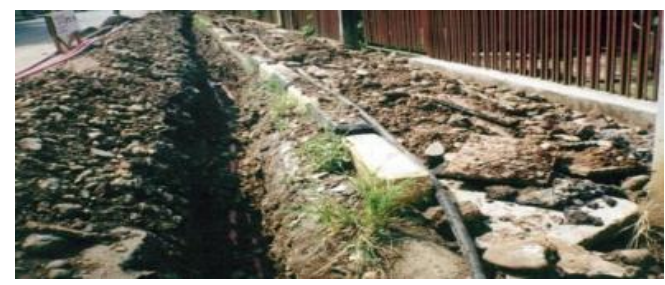

Gambar 2.3 Saluran Kabel Tegangan Menengah

Konstruksi Jaringan

Tegangan Rendah (JTR) terbagi atas :

a). Saluran Udara Tegangan Rendah

SUTR merupakan jaringan kawat yang berisolasi maupun tidak berisolasi. Bagian utama dari SUTR kawat tak berisolasi adalah tiang listrik (besi, beton). Cross Arm, Isolator dan penghantar Alumunium / Tembaga (Cu).

b). Saluran Kabel Udara Tegangan Rendah

Pada SKUTR, kabel yang digunakan adalah jenis XLPE yang lebih dikenal dengan LVTC (Low Voltage Twisted Cable). Jenis kabel ini direntangkan di antara tiang penyangga. Bagian utama adalah tiang, kabel dan suspension Clamp Bracket, yang berfungsi untuk menahan kabel pada tiang. Kabel jenis ini sekarang banyak digunakan dalam pemasangan JTR baru karena dianggap kontruksi jenis ini lebih handal.

\subsection{Konfigurasi Jaringan Tegangan Menengah}

Jaringan Tegangan Menengah dikelompokkan menjadi menjadi lima model, yaitu Jaringan Radial, Jaringan Hantaran Penghubung (Tie Line), Jaringan Lingkaran (Loop), Jaringan Spindel dan Sistem Gugus atau Kluster.

\subsection{Jaringan Tegangan Rendah}

Pada penyalurannya dilakukan dengan menggunakan sistem tiga fasa 
empat kawat yang dilengkapi netral. PLN sendiri menggunakan tegangan rendah 380/220 V dimana tegangan $380 \mathrm{~V}$ merupakan besar tegangan antar fasa dan tegangan $220 \mathrm{~V}$ merupakan tegangan fasa netral.

Konstruksi Jaringan Tegangan Rendah (JTR) terbagi atas :

a). Saluran Udara Tegangan Rendah

SUTR merupakan jaringan kawat yang berisolasi maupun tidak berisolasi. Bagian utama dari SUTR kawat tak berisolasi adalah tiang listrik (besi, beton). Cross Arm, Isolator dan penghantar Alumunium / Tembaga (Cu).

b). Saluran Kabel Udara Tegangan

Rendah

Pada SKUTR, kabel yang digunakan adalah jenis XLPE yang lebih dikenal dengan LVTC (Low Voltage Twisted Cable). Jenis kabel ini direntangkan di antara tiang penyangga. Bagian utama adalah tiang, kabel dan suspension Clamp Bracket, yang berfungsi untuk menahan kabel pada tiang. Kabel jenis ini sekarang banyak digunakan dalam pemasangan JTR baru karena dianggap kontruksi jenis ini lebih handal.

\subsection{Jatuh Tegangan (Drop Voltage)}

Tegangan jatuh pada penghantar semakin besar jika arus di dalam penghantar semakin besar dan jika tahanan penghantar semakin besar pula.

Tegangan jatuh merupakan penanggung jawab terjadinya kerugian pada penghantar karena dapat menurunkan tegangan pada beban. Akibatnya hingga berada di bawah tegangan nominal yang dibutuhkan.

Sesuai standar tegangan yang ditentukan oleh PLN, perancangan jaringan dibuat agar jatuh tegangan diujung diterima 10\%. Tegangan jatuh pada jaringan disebabkan adanya rugi tegangan akibat hambatan listrik $(\mathrm{R})$ dan reaktansi $(X)$. Jatuh tegangan phasor $V_{d}$ pada suatu penghantar yang mempunyai impedansi (Z) dan membawa arus (I) dapat dijabarkan dengan rumus :

Jatuh tegangan $(\Delta \mathrm{V})$ adalah selisih antara tegangan kirim $\left(V_{k}\right)$ dengan tegangan terima $\left(V_{T}\right)$, maka jatuh tegangan sebagai berikut :

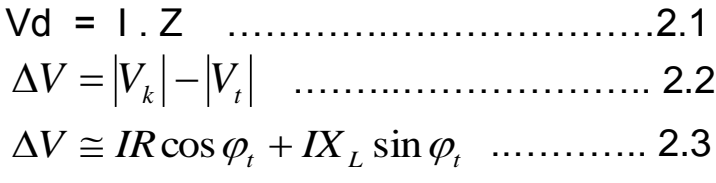

\subsection{Peramalan Beban}

Penjadwalan sistem distribusi memerlukan prakiraan (forecasting) beban masa depan. Kualitas dan akurasi penjadwalan sistem tergantung pada kualitas dan akurasi data dan prakiraan beban. Dalam penjadwalan sistem distribusi meliputi penentuan ukuran, lokasi dan perubahan waktu masa depan, seperti sejumlah komponen-komponen sistem (substation, saluran, penyulang, dan sebagainya). Lokasi geografis beban-beban dianalisa menggunakan pendekatan area yang kecil (small area), yang mana dibagi daerah pelayanan utilitas ke dalam sejumlah area kecil dan prakiraan beban pada setiap salah satunya, oleh sebab itu akan dapat ditentukan dimana dan berapa banyak yang akan dikembangkan.

\subsection{Pemilihan Letak Gardu}

Letak gardu dipengaruhi oleh beberapa faktor seperti jarak dari pusat beban, jarak dari jaringan sub-transmisi yang ada dan adanya batasan-batasan seperti tersedianya lahan, investasi yang harus digunakan, dan aturan penggunaan lahan. Lokasi ideal gardu mengikuti pandangan-pandangan sebagai berikut :

1). Lokasi gardu tersebut sebanyak mungkin melingkupi sejumlah beban.

2). Dapat memberikan level tegangan yang baik.

3). Mampu memberikan akses yang baik untuk incoming saluran sub-transmisi dan outgoing penyulang primer.

4). Mempunyai ruang yang cukup untuk pengembangan.

5). Tidak bertentangan dengan aturan tata guna lahan.

6). Dapat meminimisasi jumlah konsumen yang terpengaruh terhadap adanya gangguan.

7). Kemudahan instalasi.

\subsection{Faktor Penilaian Beban}

Faktor-faktor penilaian beban adalah faktor yang dapat memberikan gambaran mengenai karakteristik beban, baik dari segi kuantitas pembebanannya maupun 
dari segi kualitasnya. Faktor-faktor ini sangat berguna dalam meramalkan karakteristik beban masa datang atau dalam menentukan efek pembebanan terhadap kapasitas sistem secara menyeluruh.

1) Beban (Demand)

Permintaan beban diartikan sebagai besar pembebanan sesaat dan gardu pada waktu tertentu atau besar beban rata-rata untuk suatu interval waktu tertentu. Interval waktu dimana besarnya beban ingin ditentukan disebut Demand Interval (T). Demand dapat dinyatakan dalam $\mathrm{kW}, \mathrm{kVA}$ atau kVAR.

2) Beban Puncak (Peak Load)

Beban Puncak adalah nilai terbesar dari pembebanan sesaat pada suatu interval demand tertentu

3) Beban Terpasang (Connected Load) Beban terpasang dari suatu sistem adalah jumlah total daya dari seluruh peralatan sesuai dengan $\mathrm{KW}$ atau KVA yang tertulis pada papan nama (name plat) peralatan yang akan dilayani oleh sistem tersebut.

4). Faktor Kebutuhan (Demand Factor)

Faktor kebutuhan yaitu perbandingan antara beban puncak suatu sistem terhadap beban terpasang yang dilayani oleh sistem. Nilai $f_{d}$ pada prinsipnya lebih kecil atau sama dengan satu.

\section{METODE PENELITIAN}

Dalam penelitian ini, pengumpulan data dilakukan dengan cara :

a). Survei lokasi, untuk mengetahui keadaan lokasi dan status trafo.

b). Wawancara, untuk mendapat gambaran awal agar dilakukan suatu pembangunan penyulang baru dan dapat diperoleh dari pihak terkait dengan perencanaan pembangunan.

\subsection{Perkiraan Penarikan untuk Penyulang Baru}

Dengan membuat single line diagram di Gas Insulated Pantai Indah Kapuk

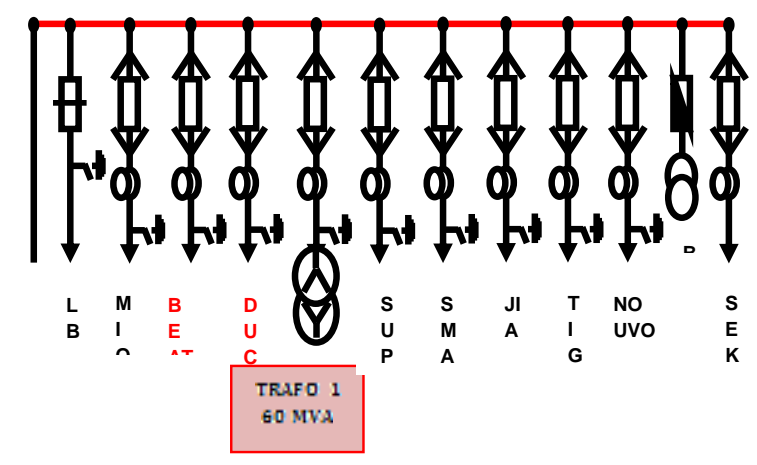

Gambar 3.1 Single Line Diagram Penyulang dari Trafo 1

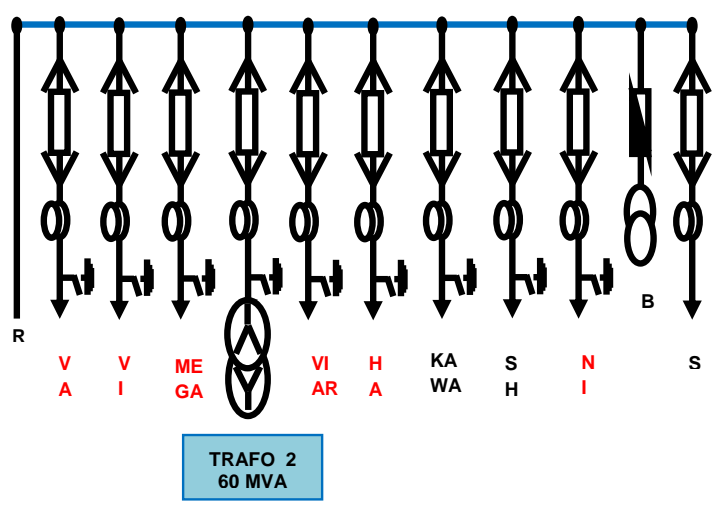

Gambar 3.2 Single Line Diagram Penyulang dari Trafo 2

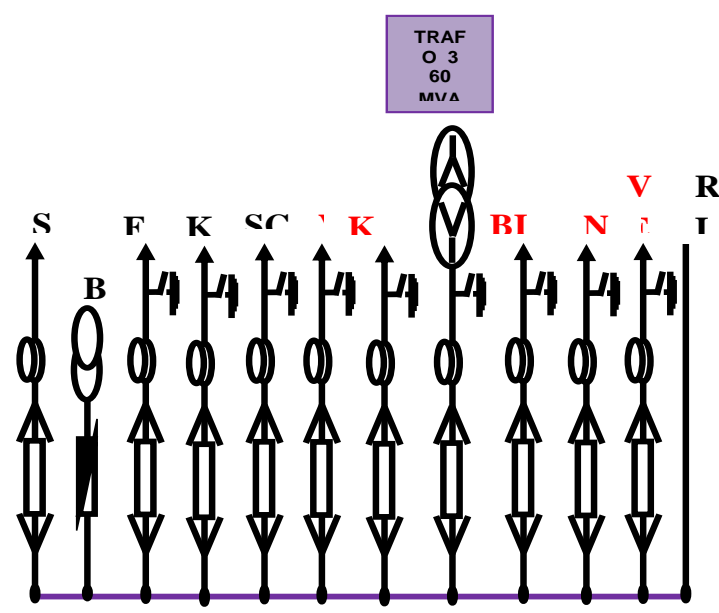

Gambar 3.3 Single Line Diagram Penyulang dari Trafo 3

Pada gambar di atas mengartikan bahwa pada penyulang berwarna merah menunjukkan penyulang yang telah beroperasi, untuk penyulang berwarna hitam menunjukkan penyulang yang masih dalam proses perencanaan. 


\subsection{Pemilihan Pemasangan Penyulang Baru}

Penyulang yang segera akan dibangun dari trafo 2 dan trafo 3 yaitu penyulang Kawasaki, Fino, Kaze, dan Scoopy. Dari keempat penyulang ini tugasnya untuk membantu menampung beban dari penyulang-penyulang lain yang berasal dari GI Duri Kosambi yaitu penyulang Hias, Puncak dan dari GI Kembangan yaitu penyulang Gesper. Dengan kapasitas trafo 2 yaitu 60 MVA dan kapasitas dari trafo 3 yaitu 60 MVA.

Tabel 3.1. Data Gardu Distribusi Penyulang Puncak

\begin{tabular}{|c|c|c|c|}
\hline No. & Gardu & $\begin{array}{c}\text { Kapasitas } \\
\text { (kVA) }\end{array}$ & $\begin{array}{c}\text { kVA } \\
\text { Terpakai }\end{array}$ \\
\hline 1 & MK277 & 400 & 299 \\
\hline 2 & MK192 & 400 & 252 \\
\hline 3 & TA108 & 630 & 171 \\
\hline 4 & TA9 & 400 & 262 \\
\hline 5 & TA67 & 1000 & 814 \\
\hline 6 & TA91 & 1000 & 638 \\
\hline 7 & KDR202 & 400 & 21 \\
\hline 8 & MK161 & 400 & 162 \\
\hline 9 & MK206 & 630 & 400 \\
\hline 10 & TA81 & 630 & 152 \\
\hline 11 & TA131P & 400 & 203 \\
\hline 12 & TA161P & 400 & 355 \\
\hline 13 & KDR69 & 630 & 126 \\
\hline 14 & KDR76 & 630 & 418 \\
\hline 15 & TA154P & 400 & 32 \\
\hline 16 & KDR76 & 400 & 139 \\
\hline 17 & TA179 & 400 & 27 \\
\hline 18 & KDR119 & 400 & 237 \\
\hline 19 & KDR189P & 400 & 95 \\
\hline 20 & KDR184 & 400 & 337 \\
\hline 21 & TA105 & 630 & 517 \\
\hline 22 & KDR66 & 630 & 417 \\
\hline 23 & MK294 & 1000 & 712 \\
\hline 24 & TA76 & 630 & 220 \\
\hline 25 & TA144P & 400 & 376 \\
\hline 26 & NS15 & 1400 & 638 \\
\hline 27 & TA82K & 400 & 103 \\
\hline 28 & TA93 & 400 & 169 \\
\hline
\end{tabular}

Tabel 3.2. Data Gardu Distribusi Penyulang Hias

\begin{tabular}{|c|c|c|c|}
\hline No. & Gardu & $\begin{array}{c}\text { Kapasitas } \\
(\text { kVA })\end{array}$ & $\begin{array}{c}\text { kVA } \\
\text { Terpakai }\end{array}$ \\
\hline 1 & BC327 & 630 & 471 \\
\hline 2 & BC294 & 630 & 521 \\
\hline 3 & KDR136 & 400 & 135 \\
\hline 4 & KDR7 & 400 & 346 \\
\hline 5 & BC45A & 1400 & 556 \\
\hline 6 & BC179 & 400 & 241 \\
\hline 7 & BC284 & 400 & 236 \\
\hline 8 & BC171 & 630 & 439 \\
\hline 9 & BC311 & 1260 & 406 \\
\hline 10 & BC315 & 630 & 307 \\
\hline 11 & BC46AS & 400 & 373 \\
\hline
\end{tabular}

\begin{tabular}{|c|c|c|c|}
\hline 12 & KDR69 & 630 & 98 \\
\hline 13 & BC216 & 800 & 275 \\
\hline 14 & BC321 & 800 & 302 \\
\hline 15 & TA145P & 400 & 279 \\
\hline 16 & KDR44P & 400 & 267 \\
\hline 17 & KDR56P & 400 & 314 \\
\hline 18 & KDR32P & 400 & 290 \\
\hline 19 & KDR231 & 400 & 51 \\
\hline 20 & KDR87 & 630 & 107 \\
\hline 21 & TA65 & 630 & 357 \\
\hline 22 & KDR77P & 400 & 264 \\
\hline 23 & BC227K & 630 & 538 \\
\hline 24 & KDR46P & 400 & 138 \\
\hline 25 & KDR70 & 630 & 243 \\
\hline 26 & BC225 & 630 & 407 \\
\hline 27 & KDR20 & 630 & 97 \\
\hline 28 & KDR135 & 400 & 133 \\
\hline 29 & KDR111 & 400 & 252 \\
\hline
\end{tabular}

Tabel 3.3. Data Gardu Distribusi Penyulang Gesper

\begin{tabular}{|c|c|c|c|}
\hline No. & Gardu & $\begin{array}{c}\text { Kapasitas } \\
\text { (kVA) }\end{array}$ & $\begin{array}{c}\text { kVA } \\
\text { Terpakai }\end{array}$ \\
\hline 1 & DK182 & 1000 & 855 \\
\hline 2 & KDR99 & 630 & 290 \\
\hline 3 & BC362 & 630 & 229 \\
\hline 4 & BC53 & 630 & 252 \\
\hline 5 & BC145 & 630 & 524 \\
\hline 6 & KDR57P & 315 & 121 \\
\hline 7 & BC39 & 630 & 215 \\
\hline 8 & KDR41 & 630 & 355 \\
\hline 9 & KDR107 & 630 & 23 \\
\hline 10 & KDR79 & 630 & 36 \\
\hline 11 & KDR52 & 400 & 184 \\
\hline 12 & KDR259 & 400 & 54 \\
\hline 13 & BC331 & 1030 & 648 \\
\hline 14 & BC192 & 630 & 369 \\
\hline 15 & BC190 & 1000 & 387 \\
\hline 16 & KDR137 & 400 & 284 \\
\hline 17 & BC151 & 400 & 75 \\
\hline 18 & BC248T & 630 & 262 \\
\hline 19 & BC271 & 630 & 352 \\
\hline 20 & KDR9P & 400 & 245 \\
\hline 21 & BC139 & 400 & 101 \\
\hline 22 & BC109 & 630 & 100 \\
\hline 23 & KDR3T & 630 & 182 \\
\hline 24 & KDR110P & 400 & 371 \\
\hline 25 & KDR86P & 400 & 207 \\
\hline 26 & KDR132 & 400 & 281 \\
\hline 27 & KDR210 & 400 & 33 \\
\hline 28 & BC262 & 1630 & 393 \\
\hline 29 & KDR97 & 630 & 208 \\
\hline 30 & KDR95 & 160 & 57 \\
\hline 31 & KDR96 & 1260 & 356 \\
\hline
\end{tabular}

\section{HASIL DAN PEMBAHASAN}

\subsection{Perhitungan dan Penjadwalan Penyulang Yang Akan Dibangun}

\section{a). Tahap Survei}

Sebelum melakukan pengembangan, pertama dilakukan adalah survei lapangan. Dalam tahap survei ini, 
beberapa hal yang harus dilakukan untuk mendapatkan data yang optimal, yaitu : Survei lokasi, dan Kedua, Wawancara, untuk mendapatkan gambaran awal mengapa dilakukan pembangunan penyulang baru. Hal ini dapat diperoleh dari pihak yang terkait dengan perencanaan pengembangan pembangunan.

\section{b). Tahap Penjadwalan}

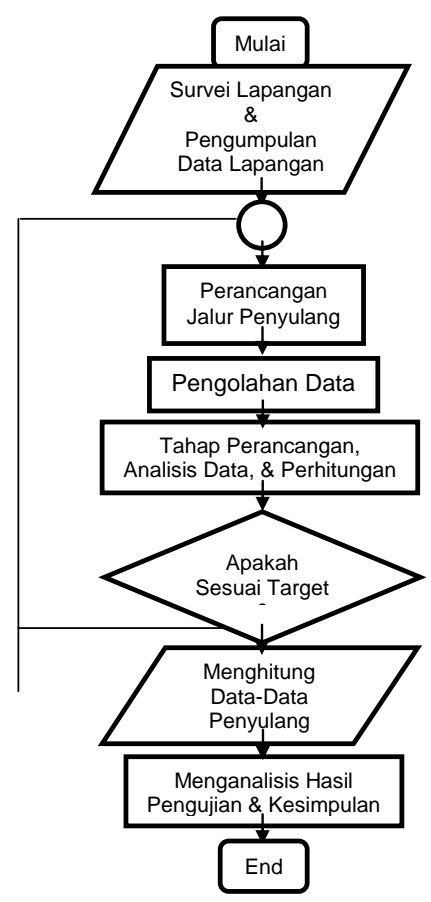

Gambar 4.1 Diagram Perencanaan

\subsection{Penentuan Lokasi Penarikan Penyulang Baru}

Keempat penyulang baru yang akan dibangun direncanakan untuk membantu menampung beban penyulang lain yang sudah beroperasi.

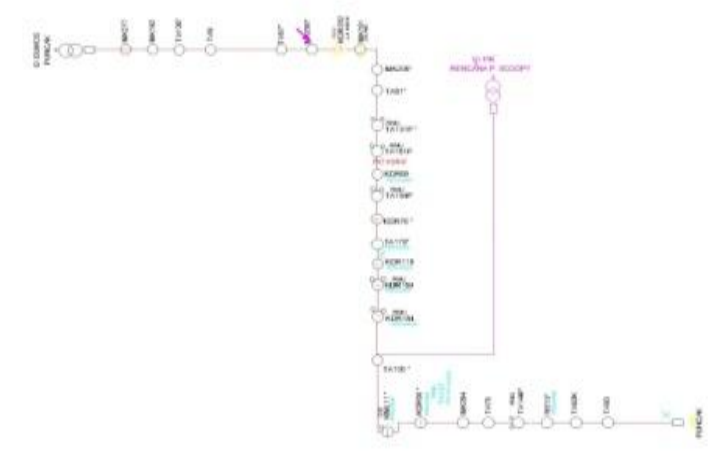

Gambar 4.2. Single Line Diagram Pecah Beban Penyulang Puncak - Scoopy

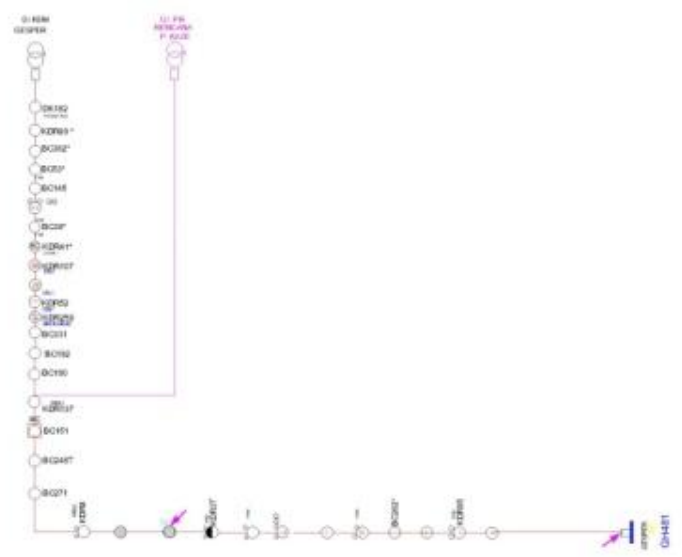

Gambar 4.3. Single Line Diagram Pecah Beban Penyulang Gesper - Kaze

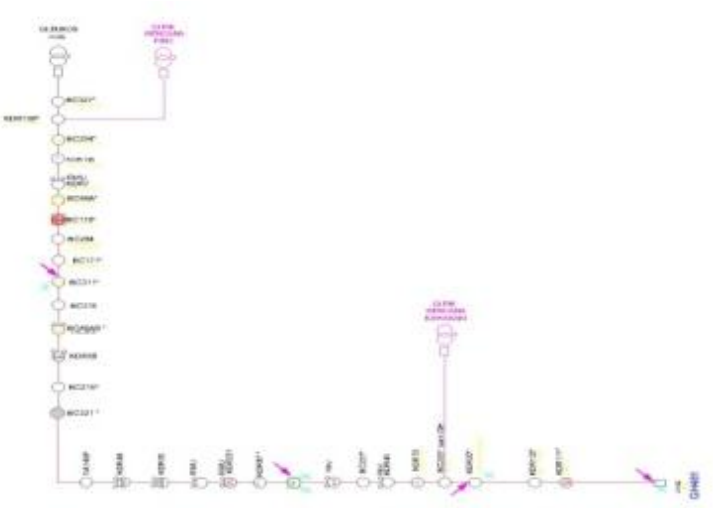

Gambar 4.5. Single Line Diagarm Pecah Beban Penyulang Hias - Fino Kawasaki

Diperkirakan dua tahun kedepan penyulang tersebut akan menampung beban hingga tiga kali lipat dari saat ini sehingga disiasatilah dengan melakukan pecah beban pada titik-titik tertentu.

Di penyulang puncak direncanakan akan pecah beban pada Gardu kode TA105 (630 kVA). Penyulang scoopy yang direncanakan akan membantu menampung beban dari Gardu Induk Duri Kosambi. Karena akan dilakukan pemisahan beban dan tidak akan tersambung lagi ke penyulang puncak, sehingga penyulang scoopy akan mengambil alih beban dari Gardu berkode TA105 hingga berakhir ke Gardu Hubung.

Di penyulang Gesper akan direncanakan pecah beban pada Gardu berkode KDR 137 (400kVA). Penyulang kaze yang direncanakan akan membantu menampung beban dari Gardu Induk Kembangan. Karena juga akan dilakukan pemisahan beban dan tidak akan tersambung lagi ke penyulang gesper, 
sehingga penyulang kaze akan mengambil alih beban dimulai dari Gardu berkode KDR 137 hingga berakhir ke Gardu Hubung.

Di penyulang Hias akan direncanakan pecah beban pada Gardu berkode BC225 (630 kVA) dan KDR199 (630 kVA). Penyulang Kawasaki dan fino yang direncanakan akan membantu menampung beban dari Gardu Induk Duri Kosambi. Karena akan dilakukan pemisahan beban dan tidak akan tersambung lagi ke penyulang hias sehingga penyulang Kawasaki dan fino akan mengambil alih masing-masing beban dari Gardu yang berkode BC 225 dan KDR 199 hingga berakhir di Gardu Hubung.

Pada jaringan tersebut semua penyulang berakhir di Gardu Hubung. Gardu Hubung sendiri berfungsi sebagai sarana manuver pengendali beban listrik jika terjadi gangguan aliran listrik, program pelaksanaan pemeliharaan atau untuk mempertahankan kontinuitas pelayanan.

Alasan dilakukan pecah beban di lokasi yang sudah ditentukan dan mengapa tidak di lokasi lain adalah karena jarak titik penyulang yang sudah ditentukan merupakan lokasi yang terdekat dari posisi penyulang baru yang akan dipasang.

\subsection{Pemilihan Jenis Penyulang dan Konfigurasinya.}

Pemilihan penyulang baru ini direncanakan akan bertipe saluran kabel tegangan menengah (SKTM). Maka daripada itu dibutuhkan juga kabel baru. Kabel yang akan digunakan adalah kabel $X$-Cross Linked Poly Ethylene (XLPE) $3 \times 240 \mathrm{~mm}^{2}$ yang berpenghantar Alumunium (Al).

Beberapa alasan mengapa akan dibangun penyulang Saluran Kabel Tegangan Menengah (SKTM) antara lain adalah :

- Karena SKTM tidak mudah mengalami gangguan.

- Tidak mengganggu keindahan lingkungan karena berada dibawah tanah.

- Tidak mudah dipengaruhi oleh cuaca (hujan,petir, dll).
- Faktor keselematan jiwa terjamin karena tidak akan terjangkau masyarakat.

Dibalik itu juga ada beberapa kekurangan jika dibangun SKTM antara lain :

- Biaya untuk membangun SKTM tergolong mahal dibandingkan SUTM.

- Jikalau mengalami gangguan maka itu adalah gangguan permanen.

- Pencarian lokasi gangguan jauh lebih sulit dibandingkan SUTM.

Untuk tipe konstruksi yang akan dirancang adalah tipe jaringan spindle.

\subsection{Data Saluran Penyulang Lama}

Perhitungan dilakukan dengan acuan penyulang lama dengan $\operatorname{Cos} \varphi$ setiap beban di asumsikan 0,85. Penghantar pada penyulang Adyaksa dengan jenis kabel XLPE (Cross-Linked Polyethylene) dengan penampang $240 \mathrm{~mm}^{2}$ dan impedansi $Z=(0,125+j 0,097) \Omega / \mathrm{km}$. Dengan acuan di atas maka, nilai impedansi saluran penghantar dapat dihitung dengan persamaan :

$$
Z=L x\left(R+j X_{L}\right)
$$

Tabel 4.1. Impedansi Penghantar Penyulang Puncak

\begin{tabular}{|c|c|c|c|c|c|c|c|c|}
\hline \multirow{2}{*}{ No } & \multirow{2}{*}{ Identitas } & \multicolumn{2}{|c|}{ Arah } & \multirow{2}{*}{$\begin{array}{l}\text { Jenis } \\
\text { Kabel }\end{array}$} & \multirow{2}{*}{$\begin{array}{l}\text { Penam } \\
\text { pang } \\
\left(\mathrm{mm}^{2}\right)\end{array}$} & \multirow{2}{*}{$\begin{array}{c}\text { L } \\
\text { Kabel } \\
(\mathrm{km})\end{array}$} & \multicolumn{2}{|c|}{$\begin{array}{c}\text { Impedansi } \\
Z=(R+j X) \Omega\end{array}$} \\
\hline & & Dari & $\mathrm{Ke}$ & & & & R & $x$ \\
\hline 1 & Seksi 1 & Kios Puncak & MK277 & XLPE & 240 & 0.823 & 0.102 & 0.079 \\
\hline 2 & Seksi2 & MK277 & MK192 & XLPE & 240 & 0.382 & 0.047 & 0.037 \\
\hline 3 & Seksi 3 & MK192 & TA108 & XLPE & 240 & 0.379 & 0.047 & 0.036 \\
\hline 4 & Seksi 4 & TA108 & TA9 & XLPE & 240 & 0.52 & 0.065 & 0.050 \\
\hline 5 & Seksi 5 & TA9 & TA67 & XLPE & 240 & 1.17 & 0.146 & 0.113 \\
\hline 6 & Seksi 6 & TA67 & TA91 & XLPE & 240 & 0.391 & 0.048 & 0.037 \\
\hline 7 & Seksi 7 & TA91 & KDR202 & XLPE & 240 & 0.481 & 0.060 & 0.046 \\
\hline 8 & Seksi 8 & KDR202 & MK161 & XLPE & 240 & 0.276 & 0.034 & 0.026 \\
\hline 9 & Seksi 9 & MK161 & MK206 & XLPE & 240 & 0.549 & 0.068 & 0.053 \\
\hline 10 & Seksi 10 & MK206 & TA81 & XLPE & 240 & 0.377 & 0.047 & 0.036 \\
\hline 11 & Seksi 11 & TA81 & TA131P & XLPE & 240 & 0.521 & 0.065 & 0.050 \\
\hline 12 & Seksi 12 & TA131P & TA161P & XLPE & 240 & 0.383 & 0.047 & 0.037 \\
\hline 13 & Seksi 13 & TA161P & KDR69 & XLPE & 240 & 0.395 & 0.049 & 0.038 \\
\hline 14 & Seksi 14 & KDR69 & KDR76 & XLPE & 240 & 0.367 & 0.045 & 0.035 \\
\hline 15 & Seksi 15 & KDR76 & TA154P & XLPE & 240 & 0.469 & 0.058 & 0.045 \\
\hline 16 & Seksi 16 & TA154P & KDA76 & XLPE & 240 & 0.388 & 0.048 & 0.037 \\
\hline 17 & Seksi 17 & KDR76 & TA179 & XLPE & 240 & 0.371 & 0.046 & 0.035 \\
\hline 18 & Seksi 18 & TA179 & KDR119 & XLPE & 240 & 0.531 & 0.066 & 0.051 \\
\hline 19 & Seksi 19 & KDR119 & KDR189P & XLPE & 240 & 0.692 & 0.086 & 0.067 \\
\hline 20 & Seksi 20 & KDR189P & KDR184 & XLPE & 240 & 0.991 & 0.123 & 0.096 \\
\hline 21 & Seksi21 & KDR184 & TA10S & XLPE & 240 & 0.525 & 0.065 & 0.050 \\
\hline 22 & Seksi 22 & TA105 & KDR66 & XLPE & 240 & 0.724 & 0.090 & 0.070 \\
\hline 23 & Seksi 23 & KDR66 & MK294 & XLPE & 240 & 0.417 & 0.052 & 0.040 \\
\hline 24 & Seksi 24 & MK294 & TA76 & XLPE & 240 & 0.521 & 0.065 & 0.050 \\
\hline 25 & Seksi 25 & TA76 & TA144P & XLPE & 240 & 0.582 & 0.072 & 0.056 \\
\hline 26 & Seksi 26 & TA144P & NS15 & XLPE & 240 & 0.499 & 0.062 & 0.048 \\
\hline 27 & Seksi 27 & NS15 & TA82K & XLPE & 240 & .0 .487 & 0.060 & 0.047 \\
\hline 28 & Seksi 28 & TA82K & TA93 & XLPE & 240 & 0.492 & 0.061 & 0.047 \\
\hline 29 & Seksi 29 & TA93 & GH172 & XLPE & 240 & 1.2 & 0.15 & 0.114 \\
\hline
\end{tabular}


Tabel 4.2 Impedansi Penghantar Penyulang Hias

\begin{tabular}{|c|c|c|c|c|c|c|c|c|}
\hline \multirow{2}{*}{ No } & \multirow{2}{*}{ Identitas } & \multicolumn{2}{|c|}{ Arah } & \multirow{2}{*}{$\begin{array}{l}\text { Jenis } \\
\text { Kabel }\end{array}$} & \multirow{2}{*}{$\begin{array}{l}\text { Penamp } \\
\text { ang } \\
\left(\mathrm{mm}^{2}\right)\end{array}$} & \multirow{2}{*}{$\begin{array}{l}\mathrm{L} \\
\text { Kabel } \\
(\mathrm{km})\end{array}$} & \multicolumn{2}{|c|}{$\begin{array}{c}\text { Impedansi } \\
Z=(R+j X) \Omega\end{array}$} \\
\hline & & Dari & $\mathrm{Ke}$ & & & & R & $x$ \\
\hline 1 & Seksi 1 & Kios Hias & BC327 & XLPE & 240 & 0.973 & 0.121 & 0.094 \\
\hline 2 & Seksi2 & $B C 327$ & BC294 & XLPE & 240 & 0.726 & 0.065 & 0.050 \\
\hline 3 & Seksi 3 & $B C 294$ & KDR136 & XLPE & 240 & 0.485 & 0.060 & 0.047 \\
\hline 4 & Seksi 4 & KDR136 & KDR7 & XLPE & 240 & 0.424 & 0.053 & 0.041 \\
\hline 5 & Seksi 5 & KDR7 & $B C 45 A$ & XLPE & 240 & 0.757 & 0.069 & 0.054 \\
\hline 6 & Seksi 6 & $B C 45 A$ & BC179 & XLPE & 240 & 0.972 & 0.046 & 0.036 \\
\hline 7 & Seksi 7 & BC179 & BC284 & XLPE & 240 & 0.481 & 0.047 & 0.036 \\
\hline 8 & Seksi 8 & BC284 & BC171 & XLPE & 240 & 0.822 & 0.040 & 0.031 \\
\hline 9 & Seksi 9 & $B C 171$ & BC311 & XLPE & 240 & 0.492 & 0.049 & 0.038 \\
\hline 10 & Seksi 10 & $B C 311$ & BC315 & XLPE & 240 & 0.477 & 0.047 & 0.036 \\
\hline 11 & Seksi 11 & BC315 & BC46AS & XLPE & 240 & 0.412 & 0.051 & 0.039 \\
\hline 12 & Seksi 12 & BC46AS & KDR69 & XLPE & 240 & 0.773 & 0.046 & 0.036 \\
\hline 13 & Seksi 13 & KDR69 & $B C 216$ & XLPE & 240 & 0.441 & 0.042 & 0.033 \\
\hline 14 & Seksi 14 & BC216 & BC321 & XLPE & 240 & 0.749 & 0.056 & 0.043 \\
\hline 15 & Seksi 15 & BC321 & TA145P & XLPE & 240 & 0.417 & 0.052 & 0.040 \\
\hline 16 & Seksi 16 & TA145P & KDR44P & XLPE & 240 & 1.129 & 0.141 & 0.109 \\
\hline 17 & Seksi 17 & KDR44P & KDR56P & XLPE & 240 & 0.734 & 0.091 & 0.071 \\
\hline 18 & Seksi 18 & KDR56P & KDR32P & XLPE & 240 & 0.922 & 0.090 & 0.070 \\
\hline 19 & Seksi 19 & KDR32P & KDR231 & XLPE & 240 & 0.683 & 0.085 & 0.066 \\
\hline 20 & Seksi 20 & KDR231 & KDR87 & XLPE & 240 & 0.671 & 0.083 & 0.065 \\
\hline 21 & Seksi 21 & KDR87 & TA65 & XLPE & 240 & 0.772 & 0.071 & 0.055 \\
\hline 22 & Seksi 22 & TA65 & KDR77P & XLPE & 240 & 0.948 & 0.056 & 0.043 \\
\hline 23 & Seksi 23 & KDR77P & BC227K & XLPE & 240 & 0.712 & 0.089 & 0.069 \\
\hline 24 & Seksi 24 & $\mathrm{BC} 227 \mathrm{~K}$ & KDR46P & XLPE & 240 & 0.833 & 0.104 & 0.080 \\
\hline 25 & Seksi 25 & KDR46P & KDR70 & XLPE & 240 & 0.972 & 0.046 & 0.036 \\
\hline 26 & Seksi 26 & KDR70 & BC225 & XLPE & 240 & 0.951 & 0.056 & 0.043 \\
\hline 27 & Seksi 27 & BC225 & KDR2O & XLPE & 240 & 0.594 & 0.061 & 0.047 \\
\hline 28 & Seksi 28 & KDR20 & KDR135 & XLPE & 240 & 0.648 & 0.106 & 0.082 \\
\hline 29 & Seksi 29 & KDR135 & KDR111 & XLPE & 240 & 0.867 & 0.033 & 0.025 \\
\hline 30 & Seksi 30 & KDR111 & GH481 & XLPE & 240 & 1.289 & 0.165 & 0.128 \\
\hline
\end{tabular}

Tabel 4.3 Impedansi Penghantar Penyulang Gesper

\begin{tabular}{|c|c|c|c|c|c|c|c|c|}
\hline \multirow{2}{*}{ No } & \multirow{2}{*}{ Identitas } & \multicolumn{2}{|c|}{ Arah } & \multirow{2}{*}{$\begin{array}{l}\text { Jenis } \\
\text { Kabel }\end{array}$} & \multirow{2}{*}{$\begin{array}{l}\text { Penam } \\
\text { pang } \\
\left(\mathrm{mm}^{2}\right)\end{array}$} & \multirow{2}{*}{$\begin{array}{l}\text { L } \\
\text { Kabel } \\
(\mathrm{km})\end{array}$} & \multicolumn{2}{|c|}{$\begin{array}{c}\text { Impedansi } \\
Z=(R+j X) \Omega\end{array}$} \\
\hline & & Dari & Ke & & & & $R$ & $\mathrm{x}$ \\
\hline 1 & Seksi 1 & Kios Gesper & DK182 & XLPE & 240 & 0.819 & 0.102 & 0.079 \\
\hline 2 & Seksi2 & DK182 & KDR99 & XLPE & 240 & 0.378 & 0.047 & 0.036 \\
\hline 3 & Seksi 3 & KDR99 & BC362 & XLPE & 240 & 0.361 & 0.045 & 0.035 \\
\hline 4 & Seksi 4 & $B C 362$ & $\mathrm{BCS} 3$ & XLPE & 240 & 0.264 & 0.033 & 0.025 \\
\hline 5 & Seksi 5 & $\mathrm{BC} 53$ & BC145 & XLPE & 240 & 0.393 & 0.049 & 0.038 \\
\hline 6 & Seksi 6 & BC145 & KDR57P & XIPE & 240 & 0.374 & 0.046 & 0.036 \\
\hline 7 & Seksi 7 & KDR57P & $8 C 39$ & XLPE & 240 & 0.317 & 0.039 & 0.030 \\
\hline 8 & Seksi 8 & $B C 39$ & KDR41 & XIPE & 240 & 0.326 & 0.040 & 0.031 \\
\hline 9 & Seksi 9 & KDR41 & KDR107 & XLPE & 240 & 0.355 & 0.044 & 0.034 \\
\hline 10 & Seksi 10 & KDR107 & KDR79 & XLPE & 240 & 0.368 & 0.046 & 0.035 \\
\hline 11 & Seksi11 & KDR79 & KDR52 & XLPE & 240 & 0.385 & 0.048 & 0.037 \\
\hline 12 & Seksi 12 & KDR52 & KDR259 & XLPE & 240 & 0.338 & 0.042 & 0.032 \\
\hline 13 & Seksi 13 & KDR259 & $B C 331$ & XLPE & 240 & 0.355 & 0.044 & 0.034 \\
\hline 14 & Seksi 14 & $B C 331$ & BC192 & XLPE & 240 & 0.389 & 0.048 & 0.037 \\
\hline 15 & Seksi 15 & BC192 & BC190 & XLPE & 240 & 0.368 & 0.046 & 0.035 \\
\hline 16 & Seksi 16 & BC190 & KDR137 & XLPE & 240 & 0.348 & 0.043 & 0.033 \\
\hline 17 & Seksi 17 & KDR137 & BC151 & XLPE & 240 & 0.485 & 0.060 & 0.047 \\
\hline 18 & Seksi 18 & $\mathrm{BC} 151$ & BC248T & XLPE & 240 & 0.338 & 0.042 & 0.032 \\
\hline 19 & Seksi 19 & BC248T & $B C 271$ & XLPE & 240 & 0.354 & 0.044 & 0.034 \\
\hline 20 & Seksi 20 & $B C 271$ & KDRgP & XLPE & 240 & 0.816 & 0.102 & 0.079 \\
\hline 21 & Seksi 21 & KDRgP & $B C 139$ & XLPE & 240 & 0.679 & 0.084 & 0.065 \\
\hline 22 & Seksi 22 & $B C 139$ & $\mathrm{BC} 109$ & XLPE & 240 & 0.983 & 0.122 & 0.095 \\
\hline 23 & Seksi 23 & BC109 & KDR3T & XLPE & 240 & 0.694 & 0.086 & 0.067 \\
\hline 24 & Seksi 24 & KDR3T & KDR110P & XLPE & 240 & 0.742 & 0.092 & 0.071 \\
\hline 25 & Seksi 25 & KDR110P & KDR86P & XLPE & 240 & 0.421 & 0.052 & 0.040 \\
\hline 26 & Seksi 26 & KDR86P & KDR132 & XLPE & 240 & 0.452 & 0.056 & 0.043 \\
\hline 27 & Seksi 27 & KDR132 & KDR210 & XLPE & 240 & 0.412 & 0.051 & 0.039 \\
\hline 28 & Seksi 28 & KDR210 & $B C 262$ & XLPE & 240 & 0.481 & 0.060 & 0.046 \\
\hline 29 & Seksi 29 & BC262 & KDR97 & XLPE & 240 & 0.439 & 0.054 & 0.042 \\
\hline 30 & Seksi 30 & KDR97 & KDR95 & XLPE & 240 & 0.387 & 0.048 & 0.037 \\
\hline 31 & Seksi 31 & KDR95 & KDR96 & XLPE & 240 & 0.524 & 0.065 & 0.050 \\
\hline 32 & Seksi 32 & KDR96 & GH481 & XLPE & 240 & 1.47 & 0.183 & 0.142 \\
\hline
\end{tabular}

\subsection{Perhitungan Tegangan di Setiap Seksi}

Tabel 4.4 Perhitungan Tegangan Setiap Seksi Penyulang Puncak

\begin{tabular}{|c|c|c|c|c|c|c|c|c|c|}
\hline \multirow{2}{*}{ No } & \multirow{2}{*}{ Seksi } & & & & \multirow[b]{2}{*}{$(\Delta V)$} & \multirow[b]{2}{*}{ In } & \multirow[b]{2}{*}{ In } \\
\hline & & R & & $z$ & & & & & \\
\hline & 277 & 02 & 79 & 0.060 & 29 & 29 & 20 & 13.042 & 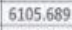 \\
\hline 2 & K192 & 047 & & $A 0$ se & & & & & \\
\hline & 1000 & & & & & & & & \\
\hline 4 & & & & & & & & & \\
\hline 3 & & & & & 140 & & & & \\
\hline 0 & & & & & 000000 & & & & \\
\hline 7 & KDR202 & 60 & & 43 & 2100 & & & 191 & \\
\hline 8 & & & & & 620 & & & & \\
\hline 9 & MK20 & & & & & & & & \\
\hline 10 & & & & & & & & & \\
\hline 11 & TA1 & & & 60 & 03 & & & & \\
\hline & TA16 & & & & & & & & \\
\hline 13 & & & & & & & & 372 & \\
\hline 14 & & & & & & & & & \\
\hline 15 & TA154P & & & & 32 & & & & \\
\hline 16 & & & & & & & & & \\
\hline 17 & TA179 & & & & & & & 15 & \\
\hline 18 & & & & & & & & & \\
\hline 19 & KDR189P & & & & & & & & \\
\hline 20 & KDR & & & & & & & & \\
\hline 2 & & & & & & & & & \\
\hline 22 & & & (v) & & & & & & 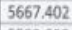 \\
\hline & & & & & & & & & \\
\hline & & & & & 2 & & & & \\
\hline & TA1 & & & & & & & & \\
\hline & & & & & & & & & \\
\hline & & & & & & & & & \\
\hline & & & 047 & & & & 30 & 909.293 & \\
\hline
\end{tabular}

Tabel 4.5 Perhitungan Tegangan Setiap Seksi Penyulang Hias

\begin{tabular}{|c|c|c|c|c|c|c|c|c|c|}
\hline \multirow[b]{2}{*}{ No } & \multirow[b]{2}{*}{ Seksi } & \multicolumn{3}{|c|}{ Impedansi } & \multirow[b]{2}{*}{ (VA) } & \multirow[b]{2}{*}{ (V) } & \multirow{2}{*}{ (AV) } & \multirow{2}{*}{$\ln { }^{\prime}$} & \multirow[b]{2}{*}{ In } \\
\hline & & R & $\mathrm{x}$ & z & & & & & \\
\hline 1 & BC327 & 0.065 & 0.050 & 0.082 & 471000 & 18314.435 & 634.404 & 14.848 & 7736.059 \\
\hline 2 & $B C 294$ & 0.060 & 0.047 & 0.076 & 521000 & 17725.949 & 588.486 & 16.969 & 7721.211 \\
\hline 3 & KDR136 & 0.053 & 0.041 & 0.067 & 135000 & 17209.707 & 516.242 & 4.529 & 7704.241 \\
\hline 4 & KDR7 & 0.069 & 0.054 & 0.088 & 346000 & 16535.070 & 674.637 & 12.061 & 7699.712 \\
\hline 5 & $B C 45 A$ & 0.046 & 0.036 & 0.058 & 556000 & 16086.017 & 4005 & 19.956 & 7687631 \\
\hline 0 & BC179 & 0.047 & 0.036 & 0.059 & 241000 & 15632.068 & 453.950 & 8.901 & 7667.675 \\
\hline 7 & BC284 & 0.040 & 0.031 & 0.051 & 236000 & 15244.485 & 37.582 & 8.938 & 7658.774 \\
\hline 8 & BC171 & 0.049 & 0.038 & 0.062 & 439000 & 14770.134 & 52 & 17.160 & 7649.836 \\
\hline 9 & BC311 & 0.047 & 0.036 & 0.059 & 406000 & 14318 & 78 & & 763 \\
\hline 10 & BC315 & 0.051 & 0.039 & 0.064 & 307000 & 13829.268 & 88 & 12.817 & 7616.305 \\
\hline 11 & BCA6AS & 0.046 & 0.036 & 0.058 & 373000 & 13385.130 & 44.137 & 16.089 & 7603.489 \\
\hline 12 & KDR69 & 0.042 & 0.033 & 0.053 & 98000 & 12979.861 & 05.269 & 4.359 & 7587.400 \\
\hline 13 & $B C 216$ & 0.056 & 0.043 & 0.071 & 275000 & 12444.464 & 55.397 & 12.758 & 7583.041 \\
\hline 14 & BC321 & 0.052 & 0.040 & 0.066 & 302000 & 1194 & 36.647 & 14.593 & 7570.282 \\
\hline 15 & TA145P & 0.141 & 0.109 & 0.178 & 279000 & 10601.249 & 1346.567 & 15.195 & 7555.689 \\
\hline 16 & KDRAAP & 0.091 & 0.071 & 0.115 & 267000 & 9730.918 & 870.331 & 15.842 & 7540.494 \\
\hline 17 & KDR56P & 0.090 & 0.070 & 0.114 & 314000 & 76 & 12 & 20.431 & 7524.653 \\
\hline 18 & KDR32P & 0.085 & 0.066 & 0.108 & 290000 & 8065.409 & 807.567 & 20.759 & 7504.221 \\
\hline 19 & KDR231 & 0.083 & 0.065 & 0.105 & 51000 & 7276.480 & 788.929 & 4.047 & 7483,462 \\
\hline 20 & KDR87 & 0.071 & 0.055 & 0.090 & 107000 & 6604.747 & 671.733 & 9.353 & 7479.416 \\
\hline 21 & TA65 & 0.056 & 0.043 & 0.071 & 357000 & 6077.327 & 527.420 & 33.915 & 7470.062 \\
\hline 22 & KDR $77 P$ & 0.089 & 0.069 & 0.113 & 264000 & 5239.909 & 837.417 & 29.088 & 7436.147 \\
\hline 23 & $B C 227 \mathrm{~K}$ & 0.104 & 0.080 & 0.131 & 538000 & 4268.031 & 971.878 & 72.777 & 7407.059 \\
\hline 24 & KDR46P & 0.046 & 0.036 & 0.058 & 138000 & 3839.619 & 428.412 & 20.751 & 7334.282 \\
\hline 25 & KDR70 & 0.056 & 0.043 & 0.071 & 243000 & 3323250 & 55,368 & 42.217 & 7313.531 \\
\hline 26 & BC225 & 0.061 & 0.047 & 0.077 & 407000 & 2763.312 & 559.938 & 85.036 & 7271.314 \\
\hline 27 & KDR2O & 0.106 & 0.082 & 0.134 & 97000 & 1800.243 & 963.069 & 31.109 & 7186.278 \\
\hline 28 & KDR135 & 0.033 & 0.025 & 0.041 & \begin{tabular}{|l|}
133000 \\
\end{tabular} & 1504.016 & 296.227 & 51.055 & 7155.170 \\
\hline 29 & KDR111 & 0.165 & 0.128 & 0.209 & 252000 & 20.480 & 1483.536 & 7104.115 & 7104.115 \\
\hline
\end{tabular}


Tabel 4.6 Perhitungan Tegangan Setiap Seksi Penyulang Gesper

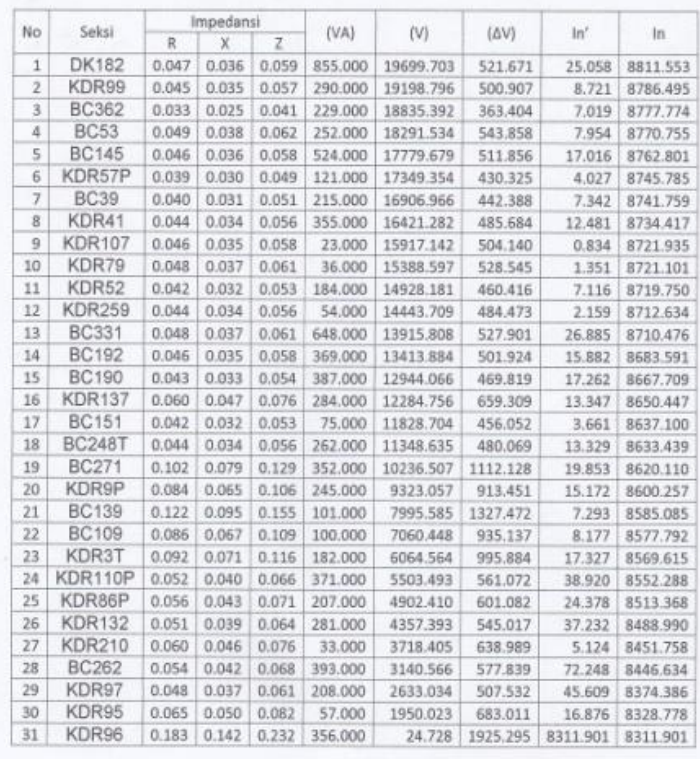

\subsection{Perkiraan Perhitungan Tegangan} Setiap Seksi Setalah Dilakukan Pemisahan Beban Pada Penyulang Puncak, Hias dan Gesper.

Tabel Perhitungan Tegangan Tiap Seksi Penyulang Hias Setelah Pecah Beban

\begin{tabular}{|r|c|c|c|c|c|c|r|}
\hline \multirow{2}{*}{ No } & \multirow{2}{*}{ Seksi } & \multicolumn{3}{|c|}{ Impedansi } & \multirow{2}{*}{ (VA) } & \multirow{2}{*}{ (V) } & \multirow{2}{*}{$(\Delta \mathrm{V})$} \\
\cline { 3 - 5 } & & $\mathrm{R}$ & $\mathrm{X}$ & \multicolumn{1}{c|}{$\mathrm{V}$} & & & \\
\hline 1 & BC327 & 0.065 & 0.050 & 0.082 & 471000 & 19616.73 & 383.268 \\
\hline 2 & BC315 & 0.051 & 0.039 & 0.064 & 307000 & 19347.74 & 268.992 \\
\hline 3 & BC46AS & 0.046 & 0.036 & 0.058 & 373000 & 19121.77 & 225.968 \\
\hline 4 & KDR69 & 0.042 & 0.033 & 0.053 & 98000 & 18935.05 & 186.719 \\
\hline 5 & BC216 & 0.056 & 0.043 & 0.071 & 275000 & 18691.88 & 243.175 \\
\hline 6 & BC321 & 0.052 & 0.040 & 0.066 & 302000 & 18483.98 & 207.9 \\
\hline 7 & TA145P & 0.141 & 0.109 & 0.178 & 279000 & 17977.03 & 506.944 \\
\hline 8 & KDR44P & 0.091 & 0.071 & 0.115 & 267000 & 17681.6 & 295.435 \\
\hline 9 & KDR56P & 0.090 & 0.070 & 0.114 & 314000 & 17419.17 & 262.428 \\
\hline 10 & KDR32P & 0.085 & 0.066 & 0.108 & 290000 & 17204.47 & 214.704 \\
\hline 11 & KDR231 & 0.083 & 0.065 & 0.105 & 51000 & 17026.18 & 178.29 \\
\hline 12 & KDR87 & 0.071 & 0.055 & 0.090 & 107000 & 16877.95 & 148.23 \\
\hline 13 & TA65 & 0.056 & 0.043 & 0.071 & 357000 & 16768.61 & 109.34 \\
\hline 14 & KDR77P & 0.089 & 0.069 & 0.113 & 264000 & 16634.93 & 133.679 \\
\hline 15 & BC227K & 0.104 & 0.080 & 0.131 & 538000 & 16514.54 & 120.389 \\
\hline 16 & KDR46P & 0.046 & 0.036 & 0.058 & 138000 & 16492.44 & 22.098 \\
\hline 17 & KDR70 & 0.056 & 0.043 & 0.071 & 243000 & 16475.19 & 17.253 \\
\hline
\end{tabular}

\begin{tabular}{|r|c|c|c|c|r|r|r|}
\hline \multirow{2}{*}{ No } & \multirow{2}{*}{ Seksi } & \multicolumn{3}{|c|}{ Impedansi } & \multirow{2}{*}{ (VA) } & \multirow{2}{*}{ (V) } & \multirow{2}{*}{ (AV) } \\
\cline { 2 - 5 } & & $R$ & $X$ & $Z$ & & & \\
\hline 1 & DK182 & 0.047 & 0.036 & 0.059 & 855.000 & 19715.266 & 284.734 \\
\hline 2 & KDR99 & 0.045 & 0.035 & 0.057 & 290.000 & 19488.919 & 226.347 \\
\hline 3 & BC362 & 0.033 & 0.025 & 0.041 & 229.000 & 19337.998 & 150.921 \\
\hline 4 & BC53 & 0.049 & 0.038 & 0.062 & 252.000 & 19123.974 & 214.024 \\
\hline 5 & BC145 & 0.046 & 0.036 & 0.058 & 524.000 & 18938.374 & 185.6 \\
\hline 6 & KDR57P & 0.039 & 0.030 & 0.049 & 121.000 & 18807.25 & 131.124 \\
\hline 7 & BC39 & 0.040 & 0.031 & 0.051 & 215.000 & 18676.945 & 130.305 \\
\hline 8 & KDR41 & 0.044 & 0.034 & 0.056 & 355.000 & 18545.905 & 131.04 \\
\hline 9 & KDR107 & 0.046 & 0.035 & 0.058 & 23.000 & 18430.775 & 115.13 \\
\hline 10 & KDR79 & 0.048 & 0.037 & 0.061 & 36.000 & 18311.093 & 119.682 \\
\hline 11 & KDR52 & 0.042 & 0.032 & 0.053 & 184.000 & 18209.015 & 102.078 \\
\hline 12 & KDR259 & 0.044 & 0.034 & 0.056 & 54.000 & 18111.463 & 97.552 \\
\hline 13 & BC331 & 0.048 & 0.037 & 0.061 & 648.000 & 18008.495 & 102.968 \\
\hline 14 & BC192 & 0.046 & 0.035 & 0.058 & 369.000 & 17948.175 & 60.32 \\
\hline 15 & BC190 & 0.043 & 0.033 & 0.054 & 387.000 & 17911.941 & 36.234 \\
\hline 16 & KDR137 & 0.06 & 0.047 & 0.076 & 284.000 & 17890.357 & 21.584 \\
\hline
\end{tabular}

Tabel 4.7. Perhitungan Tegangan Setiap Seksi Penyulang Puncak Setelah Pecah Beban

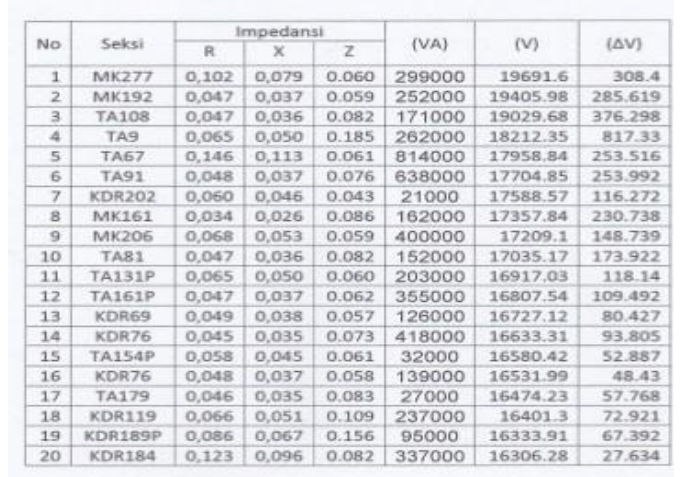

\section{KESIMPULAN}

1. Dalam pembangunan penyulang baru, syarat utama untuk tegangan ujung penyulang harus sesuai standar PLN $+5 \%$ dan $-10 \%$.

2. Untuk penyulang baru dapat dibangun bila sudah mendapat izin pembangunan dari pihak terkait, seperti (Pemda, PLN, dan Pemilik lahan yang akan dilintasi kabel penyulang).

3. Menggunakan jenis penghantar SKTM kabel XLPE dengan penghantar aluminium $240 \mathrm{~mm}^{2}$.

4. Setelah pemisahan beban dilakukan, nilai tegangan pada penyulang yang baru tentunya lebih baik dari sebelumnya.

\section{REFERENSI}

1. Djiteng Marsudi, Ir. (1990). Operasi Sistem Tenaga Listrik. Penerbit ISTN 1990, Jakarta.

2. William D., dan Stevenson, Jr. (1990). Analisis Sistem Tenaga Listrik. Penerbit Erlangga, Jakarta

3. Standar Konstruksi Jaringan Distribusi PT. PLN Persero Distribusi Jakarta Raya dan Tangerang. (1994). Buku I, II, III, IV, V, VI, Jakarta

4. Sariadi, Dkk. (1999). Jaringan Distribusi Listrik. Penerbit Angkasa, Bandung

5. Sulaso, Ir. (2001). Teknik dan Sistem Distribusi Tenaga Listrik. Badan Penerbit Universitas Diponegoro, Semarang

6. Suswanto, Daman. (2009). Sistem Distribusi Tenaga Listrik. Universitas Negeri Padang, Padang 